\title{
Horizontal-to-Vertical Spectral Ratio of Ambient Vibration Obtained with Hilbert-Huang Transform
}

\author{
Maik Neukirch $^{1, *(\mathbb{D})}$, Antonio García-Jerez ${ }^{2} \mathbb{D}$, Antonio Villaseñor ${ }^{3} \mathbb{D}$, Francisco Luzón ${ }^{2} \mathbb{D}$, Mario Ruiz $^{1}$ AD $^{\mathbb{1}}$ \\ and Luis Molina 4 (D) \\ 1 Geosciences Barcelona, GEO3BCN-CSIC, C/Lluis Solé i Sabarís s/n, 08028 Barcelona, Spain; \\ mruiz@geo3bcn.csic.es \\ 2 Department of Chemistry and Physics, University of Almería, Carretera Sacramento s/n, \\ La Cañada de San Urbano, 04120 Almería, Spain; agarcia-jerez@ual.es (A.G.-J.); fluzon@ual.es (F.L.) \\ 3 Institute of Marine Sciences, ICM-CSIC, Passeig Marítim de la Barceloneta 37-49, 08003 Barcelona, Spain; \\ antonio.villasenor@csic.es \\ 4 Department of Biology and Geology, University of Almería, Carretera Sacramento s/n, \\ La Cañada de San Urbano, 04120 Almería, Spain; lmolina@ual.es \\ * Correspondence: maik.neukirch@gmx.de
}

check for updates

Citation: Neukirch, M.; García-Jerez, A.; Villaseñor, A.; Luzón, F.; Ruiz, M.; Molina, L. Horizontal-to-Vertical Spectral Ratio of Ambient Vibration Obtained by Hilbert-Huang Transform. Sensors 2021, 21, 3292. https://doi.org/10.3390/s21093292

Academic Editor: Claudia Troise

Received: 6 April 2021

Accepted: 6 May 2021

Published: 10 May 2021

Publisher's Note: MDPI stays neutral with regard to jurisdictional claims in published maps and institutional affiliations.

Copyright: (c) 2021 by the authors. Licensee MDPI, Basel, Switzerland. This article is an open access article distributed under the terms and conditions of the Creative Commons Attribution (CC BY) license (https:/ / creativecommons.org/licenses/by/ $4.0 /)$.

\begin{abstract}
The Horizontal-to-Vertical Spectral Ratio (HVSR) of ambient vibration measurements is a common tool to explore near surface shear wave velocity (Vs) structure. HVSR is often applied for earthquake risk assessments and civil engineering projects. Ambient vibration signal originates from the combination of a multitude of natural and man-made sources. Ambient vibration sources can be any ground motion inducing phenomena, e.g., ocean waves, wind, industrial activity or road traffic, where each source does not need to be strictly stationary even during short times. Typically, the Fast Fourier Transform (FFT) is applied to obtain spectral information from the measured time series in order to estimate the HVSR, even though possible non-stationarity may bias the spectra and HVSR estimates. This problem can be alleviated by employing the Hilbert-Huang Transform (HHT) instead of FFT. Comparing 1D inversion results for FFT and HHT-based HVSR estimates from data measured at a well studied, urban, permanent station, we find that HHT-based inversion models may yield a lower data misfit $\chi^{2}$ by up to a factor of 25 , a more appropriate Vs model according to available well-log lithology, and higher confidence in the achieved model.
\end{abstract}

Keywords: HVSR; non-stationary; data processing

\section{Introduction}

The Horizontal-to-Vertical Spectral Ratio (HVSR) of ground motion measurements is a common tool to characterize near surface shear wave (Vs) structure [1-4]. It is often applied for earthquake risk assessments [5,6] and civil engineering [7,8]. HVSR relies on ambient noise as time series that can be measured with common three-component (3C) seismometers or, recently, by a combination of a seismometer for the vertical motion and fiber optic cables for finely distributed array sensing for the horizontal component [8] or even from active source seismics [9].

Ambient vibration refers to persistent, broad band ground vibrations caused by a multitude of natural and/or man-made sources. It consists mostly of elastic surface waves that originate from ocean waves, winds and human activity such as machinery, industries or public transportation to name a few [2]. Typically, the Fast Fourier Transform (FFT) is applied to obtain spectral information from the measured time series but, given the complexity and randomness of sources, the measured signal need not be sufficiently stationary and may bias FFT spectra. This may be particularly problematic in urban areas with abundant anthropogenic vibration sources of very heterogeneous origins and powers. Among the alternatives to the FFT that have been considered for non-stationary data analysis are 
wavelet analysis $[10,11]$ and the Hilbert-Huang Transform [12,13]. While wavelet analysis still requires one to choose basis functions, the Hilbert-Huang Transform (HHT) introduced by [14] is truly data adaptive and therefore, well suited for the analysis of general time series of unknown origin that include non-stationarity. HHT, and its fundamental engine, the Empirical Mode Decomposition (EMD), have become a widely used tool to analyze time series measurements that perform equally well for stationary as for non-stationary signals, e.g., [15-18]. Whether or not non-stationary signals should be removed from time series for HVSR processing is still debated between authors who consider it necessary to exclude spikes and transients in microtremors, e.g., [19-21] who suggest that non-stationary large amplitude noise windows should not be removed, because these can carry subsoil information, potentially improving the correlation between noise and earthquakes in HVSR curves. Furthermore, other authors suggest methods for the selection of time windows using statistical criteria that use agglomerative hierarchical clustering, e.g., [22,23].

EMD describes the time series based on a data-adaptive spectral basis which may vary over time, therefore each channel of a $3 \mathrm{C}$ signal is not necessarily described on the same spectral basis at all times if each component is treated as univariate, i.e., independently. This is not a problem for the FFT, which describes a time series by its spectral components by assuming a static spectral basis. Therefore the FFT can be univariate and, still, the basis will be uniform for a $3 \mathrm{C}$ signal enabling an easy calculation of the spectral ratio between different channels. Multivariate Empirical Mode Decomposition (MEMD) [24] overcomes this problem by enforcing most similar spectral bases (still data adaptive and time varying) on $3 \mathrm{C}$ signals and therewith allowing intrinsically a time varying spectral analysis of a non-stationary $3 \mathrm{C}$ signal. MEMD has been evaluated as a filter in seismology and has been reported as very effective in reducing noise for earthquake hypocenter analysis [25].

Application of the HHT for HVSR estimation has been limited to the use as a filter to remove unwanted components in the time series, which then would yield improved HVSR estimates by traditional FFT $[12,13]$. The reason for this is that the instantaneous spectral data of a $3 \mathrm{C}$ signal obtained by univariate HHT cannot be interpreted between the components due to incoherence in the spectral basis between the components. This problem can be addressed adequately by using MEMD as reported by, e.g., [25] for seismologic data and [26] for magnetotelluric data. Applying MEMD to HVSR data processing allows to utilize directly the $3 \mathrm{C}$ instantaneous spectral data and avoid FFT data processing altogether.

In this work, we illustrate the benefits that MEMD can bestow on HVSR data processing and data inversion in comparison to a process purely based on FFT. To this end, we first review the (M)EMD for the context of a 3C seismic signal, state our statistical framework for the computational estimation of the HVSR from spectral instantaneous parameters and lay out our strategy to compare MEMD and FFT results. Then, we demonstrate our findings exemplarily on data from two different sites, one field site and one permanent station. Using data from well studied stations, we corroborate our results with available well-log lithology. Our HHT-based inversion models for the permanent station yield a lower data misfit $\chi^{2}$ by a factor of 25 , a more appropriate Vs model according to the available well-log lithology, and a higher confidence in the achieved model.

\section{Methodology}

\subsection{Multivariate Empirical Mode Decomposition (MEMD)}

EMD is used in the HHT to obtain a set of zero-mean functions for each of which a physically meaningful analytic signal is guaranteed to exist. Such a zero-mean function is referred to as intrinsic mode function (IMF, denoted by the greek letter iota, $\iota$ ). Then, the analytic signal of an IMF contains the instantaneous spectral parameters (ISP), amplitude, phase and frequency that are subsequently used for spectral analyses. Let us review the basic process for EMD [14] on a time series $d(t)$ (see Figure 1) with pseudo-code:

1. Copy time series $d_{\text {temp }}=d(t)$, initialize mode index $(m=0)$ and choose a sifting tolerance (e.g., $10^{-6}$ ).

2. Copy the time series $c=d_{\text {temp }}$. 
3. Compute cubic splines through maxima and minima of $c$, these are the envelopes $c_{\max }$ and $c_{\min }$.

4. Obtain the mean of the envelopes $c_{0}=0.5\left(c_{\max }+c_{\min }\right)$ and subtract $c_{0}$ from $c$.

5. Continue if $\sum\left|c_{0}\right|$ is zero (up to a tolerance), otherwise return to point 3 .

6. Save current $c$ (from which you repeatedly subtracted $c_{0}$ ) as IMF with $m=m+1$ : $\iota_{m}=c$. Then subtract current IMF from $d_{\text {temp }}$ to obtain the new, reduced time series $d_{\text {temp }}=d_{\text {temp }}-c$

7. If $d_{\text {temp }}$ has 3 or fewer extrema continue, otherwise return to point 2.

8. Save $d_{\text {temp }}$ as residual: $r=d_{\text {temp }}$.

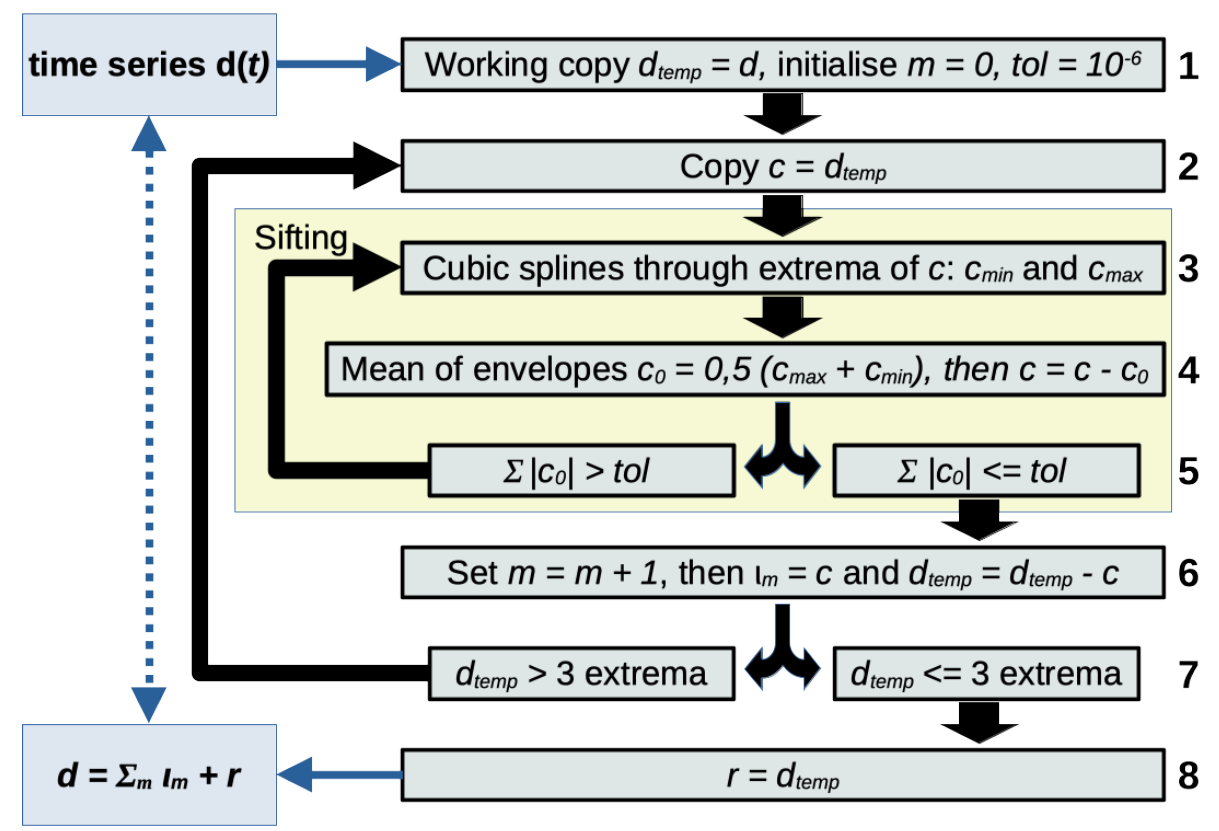

Figure 1. Basic Empirical Mode Decomposition. Note that the sifting stop criteria (point 5) above is given in its original form and various alternatives have been discussed in the literature [27]. However, the exact formulation of the stopping criteria for the sifting process (points 3 to 5 ) is not central to our work as the EMD algorithm performs with any chosen criteria.

The EMD algorithm yields a (data dependent) number of IMFs and one residual, which will, if summed up, yield the original data exactly:

$$
d(t)=\sum_{m=1}^{m_{\max }} \iota_{m}(t)+r(t)
$$

There are a number of plausible strategies to compute the analytic signal from an IMF [28] and some may be more adequate than others, depending on the nature of the data. The choice of how to compute the analytic signal is not central to this work. Originally, the Hilbert Transform is suggested to compute the corresponding imaginary part to an IMF but [28] reports that the direct quadrature (DQ) generally provides a more robust estimate of the analytic signal. In this manuscript, we use the direct quadrature, yielding a complex-valued IMF $\tilde{\imath}$ :

$$
\tilde{\iota}_{m}(t)=\iota_{m}(t)+i \mathcal{D} \mathcal{Q}\left(\iota_{m}(t)\right) .
$$

Time series of instantaneous spectral amplitude $\alpha$, phase $\phi$ and frequency $\omega$ can be derived from the IMF's analytic signal as magnitude, argument and the argument's time derivative, respectively [28]:

$$
\tilde{\iota}_{m}(t)=\alpha_{m}(t) e^{2 i \pi \phi_{m}(t)} \quad \text { and } \quad \omega_{m}(t)=2 \pi \frac{\partial \phi_{m}(t)}{\partial t}
$$


As mentioned before, the HVSR compares the spectra of horizontal and vertical ground motion measurements and, therefore requires for the spectra to be on the same spectral basis, which they are by default for the FFT. The spectral basis for ISP obtained by EMD are data dependent and it cannot be guaranteed that two different measurements, i.e., horizontal and vertical components, yield the same spectral basis. To overcome this kind of problem, Ref. [24] proposed a multivariate expansion to the EMD algorithm, referred to as MEMD. Typical $3 \mathrm{C}$ seismic ground motion measurements are trivariate signals. The multivariate variant EMD projects the multicomponent signal on hyperplanes of orthogonal sequences and performs the sifting process on these projections. Then the superposition of the sifted projections yields the multivariant IMFs which enjoy the same properties as IMFs obtained by the original EMD, specifically that physically meaningful ISPs can be generated. The advantage over the original EMD is that MEMD produces IMFs with similar instantaneous frequency, so that the multivariate signal corresponds to a common spectral basis at all times. For more details we refer to the work by [24].

\subsection{Robust, Weighted Statistics for HVSR Processing on a Logarithmic Scale}

\subsubsection{Preliminaries}

Subscripts of lowercase letters denote the elements of a matrix $x$, e.g., $x_{f, w, \ldots,}$, while capitalized subscripts distinguish cardinal directions, i.e., $E$ and $N$ for east-west and north-south, respectively. Superscripts identify elements of a list $y$, e.g., $y^{f, w, \ldots}$ which may be differently sized matrices themselves. The sum, mean and median of a matrix $x$, with elements $x_{f, w, \ldots}$, over its dimension $w$ are denoted by $\sum_{w} x_{f, w}, \ldots, \operatorname{mean}_{w}\left(x_{f, w}, \ldots\right)$ and $\operatorname{median}_{w}\left(x_{f, w}, \ldots\right)$, respectively, while the mean average deviation (MAD) to the mean, square root deviation (SRD) to the median and normalization are, respectively, defined by:

$$
\begin{gathered}
\operatorname{mad}_{w}\left(x_{f, w, \ldots}\right)=\operatorname{mean}_{w}\left(\left|x_{f, w, \ldots}-\operatorname{mean}_{w}\left(x_{f, w}, \ldots\right)\right|\right), \\
\operatorname{srd}_{w}\left(x_{f, w, \ldots}\right)=\sqrt{\left|x_{f, w, \ldots}-\operatorname{median}_{w}\left(x_{f, w, \ldots}\right)\right|}, \\
\text { normalise }_{w}\left(x_{f, w, \ldots}\right)=\frac{x_{f, w, \ldots}}{\sum_{w} x_{f, w, \ldots}} .
\end{gathered}
$$

It is worth noting here that MAD and SRD are robust statistical instruments implemented to weight data and safeguard from strong outliers. We use MAD as robust estimate of the standard deviation and its square for the variance. Later we will assign data weights based on inverse variances, which are in fact estimated by MAD. The SRD describes how close a datum point is to the expected value of the entire data set and we transform this information to a data weight similar to a typical weight function based on residuals (deviations) in robust regression, where outliers receive a smaller weight that is calculated from a function of the inverse deviation (e.g., Huber weights).

Lastly, given weights $\rho_{f, w}$ for each datum, the weighted covariance matrix [29] for data matrix $x_{f, w}$ at time window $w$ and frequency bins $f_{1}$ and $f_{2}$ is defined by:

$$
C_{f_{1}, f_{2}}\left(\rho_{f, w}, x_{f, w}\right)=\frac{\sum_{w}\left(x_{f_{1}, w}-\sum_{w}\left(\rho_{f_{1}, w} x_{f_{1}, w}\right)\right)\left(\rho_{f_{2}, w}\left(x_{f_{2}, w}-\sum_{w}\left(\rho_{f_{2}, w} x_{f_{2}, w}\right)\right)\right)}{1-\sum_{w} \rho_{f_{2}, w}^{2}} .
$$

\subsubsection{HVSR Processing Scheme}

Given a $3 C$ time series of ground motion at a location, we refer to $e(t), n(t)$ and $z(t)$ to the time domain measurements in east-west, north-south and vertical direction, respectively. Before the processing, we divide the time series into $W$ equal windows (e.g., $15 \mathrm{~min}$ intervals) and prepare $F$ logarithmically equally spaced frequency bins over the period range of interest.

We compute the ISPs for the trivariate signal $\left[e^{w}(t), n^{w}(t), z^{w}(t)\right]$ for each window $w$ by means of MEMD and assign the instantaneous spectral amplitudes to a corresponding 
frequency bin $f$ based on the common instantaneous frequency. We take into account that the assigned ISPs in each bin are independent and identically distributed by selecting only one data point between zero crossings, following instructions by [26]

Let us denote the binned spectral amplitudes for all windows by $E^{f, w}, N^{f, w}$ and $Z^{f, w}$. The exact number of samples, $s(f, w)$, within each $E^{f, w}, N^{f, w}$ and $Z^{f, w}$ varies depending on the signal found in each window but, generally, lower frequencies will contain less samples while different windows at the same frequency will contain a similar amount of samples. Then, lists of directional (natural) logarithmic HVSR of all samples at each window $w$ and for each frequency bin $f$ are given by:

$$
\Lambda^{f, w, E}=\ln \left(E^{f, w}\right)-\ln \left(Z^{f, w}\right) \quad \text { and } \quad \Lambda^{f, w, N}=\ln \left(N^{f, w}\right)-\ln \left(Z^{f, w}\right) .
$$

Means and MADs are computed over all samples as representative values for each window and frequency:

$$
\begin{array}{rrr}
\bar{\Lambda}_{f, w, E}=\operatorname{mean}_{s(f, w)}\left(\Lambda_{s(f, w)}^{f, w w}\right) & \text { and } & \bar{\Lambda}_{f, w, N}=\operatorname{mean}_{s(f, w)}\left(\Lambda_{s(f, w)}^{f, w, N}\right) \\
\Delta_{f, w, E}=\operatorname{mad}_{s(f, w)}\left(\Lambda_{s(f, w)}^{f, w}\right) & \text { and } & \Delta_{f, w, N}=\operatorname{mad}_{s(f, w)}\left(\Lambda_{s(f, w)}^{f, w, E}\right)
\end{array}
$$

Considering each element of $\bar{\Lambda}$ as a datum for the logarithmic, root squared average HVSR data yield:

$$
\bar{\lambda}_{f, w}=0.5 \ln \left(\exp \left(2 \bar{\Lambda}_{f, w, E}\right)+\exp \left(2 \bar{\Lambda}_{f, w, N}\right)\right) .
$$

Additionally to the datum's confidence estimate $\Delta$ from the MAD over all samples within each window, we compute for each datum the SRD to the data median over all windows with (5):

$$
\delta_{f, w, E}=\operatorname{srd}_{w}\left(\bar{\Lambda}_{f, w, E}\right) \quad \text { and } \quad \delta_{f, w, N}=\operatorname{srd}_{w}\left(\bar{\Lambda}_{f, w, N}\right) .
$$

While the MAD robustly and independently describes each datum's confidence based on each window's spectral amplitudes (datum precision), the SRD provides a robust confidence estimate for each datum's reliability across all windows (datum accuracy). We combine both to an overall confidence estimate

$$
c_{f, w}=\left(\delta_{f, w, E} \Delta_{f, w, E}^{2} \delta_{f, w, N} \Delta_{f, w, N}^{2}\right)^{-\frac{1}{2}}
$$

and assign weights $\rho$ to each datum derived from the normalized confidence estimates with (6):

$$
\rho_{f, w}=\text { normalise }_{w}\left(c_{f, w}\right) .
$$

Then, the weighted, overall, logarithmic HVSR curve is given by:

$$
\lambda_{f}=\sum_{w}\left(\rho_{f, w} \bar{\lambda}_{f, w}\right)
$$

the weighted covariance matrix $C\left(\rho_{f, w}, \bar{\lambda}_{f, w}\right)$ is obtained by (7) and the weighted standard deviation for the overall logarithmic HVSR curve at each frequency is given by:

$$
\sigma_{f}=\sqrt{C_{f, f}} .
$$

Lastly, if needed, linear HVSR estimates and their lower/upper confidence bounds are, respectively,

$$
\mathrm{HV}_{f}^{0}=e^{\lambda_{f}}, \quad \mathrm{HV}_{f}^{-}=e^{\lambda_{f}-\sigma_{f}} \quad \text { and } \quad \mathrm{HV}_{f}^{+}=e^{\lambda_{f}+\sigma_{f}}
$$




\subsection{Comparison between FFT- and MEMD-Based HVSR Results}

Constructing realistic, complex synthetic ambient noise data is a daunting task which would require to solve a simulation with many variables. The solution for such a complex physical problem would require to set simplifying assumptions for which, in turn, any conclusions would be of limited value, as the question would remain as whether or not assumptions made for the modeling would be representative and general enough for real data. While we could easily invent a non-stationary noise source that is able to disrupt the FFT but not MEMD, e.g., [30], such noise would be very specific and would not necessarily exist in the real world. Therefore, we prefer to demonstrate the performance of MEMD on real data.

However, it is difficult to compare two processing algorithms with real data, because the true result is generally not known. In order to avoid both, constructing unrealistic synthetic data and comparing different results of real data not knowing which one is true, we opt to use real data and go one step further by inverting the processing results. The inverted $V_{S}$ models can be more easily compared. While this strategy adds more unknowns to the comparison, it allows us to make use of existing complementary data such as well-logs and Vs models from other sources with which we can corroborate the inverted models obtained from the processing results of each processing method. Specifically, in the following examples, we will assign shear wave velocity ranges taken from existing studies to concrete layers identified from well-log lithology to generate a large number of reasonable starting models. Using the starting models, the inversion results for both algorithms' HVSR data are compared based on the achieved $\chi^{2}$, model confidence and the models' ability to represent the known lithology qualitatively.

\section{Examples}

3.1. Tests at the Station ICJA at Geoscience Barcelona, Spain

\subsubsection{Introduction and A-Priori Information}

ICJA is a permanently installed Trillium 120 broad band seismometer [31]. It is installed in the basement of the Geoscience Barcelona (GEO3BCN-CSIC) building situated in the university district in Barcelona, Spain, a dense and busy urban environment [32,33]. Reports on the site's Vs structure [34] and a well-log with a lithologic column are available [35]. Table 1 summarizes the well-log lithology into 11 layers and displays the starting model parameter ranges for the inversions that we will describe later. The starting model parameter range has been determined based on expected values for the given lithologic units, and only the sedimentary units, i.e., silty sand and clayey sand, have been given unusually large values because [34] report Vs velocities of around $1000 \mathrm{~ms}^{-1}$ at these depths. During the inversions, Vs values are allowed to range from $50 \mathrm{~ms}^{-1}$ to $4000 \mathrm{~ms}^{-1}$ for all layers.

Table 1. Well-log lithology and HVSR inversion initial and final Vs models from the ICJA station are summarized. 350 initial models were generated randomly in the range $v_{i} \pm \Delta v_{i}$. During the inversion, model parameters had to remain within the given bounds. Best model, $v_{\text {best }}$, and mean model with standard deviation, $\bar{v} \pm \sigma_{v}$, resulted from the inversion of data processed by the two different algorithms, FFT and MEMD.

\begin{tabular}{|c|c|c|c|c|c|c|c|}
\hline \multirow[b]{2}{*}{ Lithology } & \multirow{2}{*}{$\begin{array}{l}\text { Top } \\
{[\mathrm{m}]}\end{array}$} & \multicolumn{2}{|c|}{ Starting Model Vs [m/s] } & \multicolumn{2}{|c|}{ FFT Vs $[\mathrm{m} / \mathrm{s}]$} & \multicolumn{2}{|c|}{ MEMD Vs $[\mathrm{m} / \mathrm{s}]$} \\
\hline & & $v_{i} \pm \Delta v_{i}$ & Bounds & $v_{\text {best }}$ & $\bar{v} \pm \sigma_{v}$ & $v_{\text {best }}$ & $\bar{v} \pm \sigma_{v}$ \\
\hline Foundation & 0.0 & $1700 \pm 400$ & 50 to 4000 & 1440 & $1200 \pm 180$ & 1490 & $1510 \pm 170$ \\
\hline Silt, Sand & 2.5 & $1000 \pm 300$ & 50 to 4000 & 1000 & $780 \pm 110$ & 920 & $960 \pm 90$ \\
\hline Clay, Sand & 28.0 & $1000 \pm 300$ & 50 to 4000 & 920 & $820 \pm 70$ & 940 & $1000 \pm 70$ \\
\hline Weath. S1. & 41.0 & $900 \pm 300$ & 50 to 4000 & 810 & $850 \pm 90$ & 990 & $1020 \pm 130$ \\
\hline Slate. & 47.0 & $1300 \pm 300$ & 50 to 4000 & 1260 & $1240 \pm 60$ & 1160 & $1220 \pm 50$ \\
\hline Schist & 77.5 & $2500 \pm 500$ & 50 to 4000 & 2790 & $2490 \pm 340$ & 2330 & $2350 \pm 300$ \\
\hline Slate & 90.5 & $1300 \pm 300$ & 50 to 4000 & 1750 & $1220 \pm 280$ & 1080 & $1270 \pm 220$ \\
\hline Limestone & 108.5 & $2500 \pm 500$ & 50 to 4000 & 2500 & $2160 \pm 360$ & 1940 & $2030 \pm 280$ \\
\hline Slate & 138.5 & $1600 \pm 500$ & 50 to 4000 & 1750 & $1720 \pm 220$ & 1580 & $1720 \pm 130$ \\
\hline Hornfels & 188.0 & $2500 \pm 500$ & 50 to 4000 & 3430 & $2640 \pm 430$ & 2530 & $2650 \pm 270$ \\
\hline Slate & 202.5 & $2000 \pm 500$ & 50 to 4000 & 2690 & $2050 \pm 280$ & 1790 & $2010 \pm 240$ \\
\hline
\end{tabular}




\subsubsection{Data Preparation and Processing}

Although the station ICJA continuously collects data at $250 \mathrm{~Hz}$, for the purpose of testing and comparing our algorithm, we selected the $3 \mathrm{C}$ measurements of a single day. The chosen day is Easter Sunday 2017, a presumingly quiet day in the middle of a revered holiday season by students, staff and scientists alike. The whole day's data have been divided into 96 intervals of $15 \mathrm{~min}$.

Geopsy [36] has been used to compute the FFT-based H/V. This is a widely used toolset for this task (among many other capacities) originated from the [37] project and continuously maintained ever since. Geopsy's HVSR tool follows the traditional approach of using windowed FFT for spectra generation and, therefore, it relies on the assumption that the measured time series are sufficiently stationary during these windows.

At 43 frequencies in the range from 0.5 to $20 \mathrm{~Hz}$, we obtain windowed HVSR estimates for both methods which are used to determine a weighted average result for the day, including data confidence in the form of the covariance matrix as described in the previous section. We use Geopsy's default settings, except for the 30 s non-overlapping Tukey windows employed to obtain estimates for each $15 \mathrm{~min}$ interval and the computation of the total (not averaged) horizontal power in accordance with our results and the input of our inversion routine. Similarly, MEMD estimates were computed for each 15 min interval's ISPs. It needs mentioning that our approach with MEMD took $3 \mathrm{~h}$ on a standard laptop (2.2 GHz 6-Core) to provide estimates, while Geopsy computation time was tens of seconds (for the entire day of data without segmenting into separate $15 \mathrm{~min}$ intervals which cannot be automated currently). While this ratio may improve if MEMD software were to be optimized, it would likely remain a significant discrepancy in computation time between the methods. Processing results for both methods are illustrated in Figure 2.

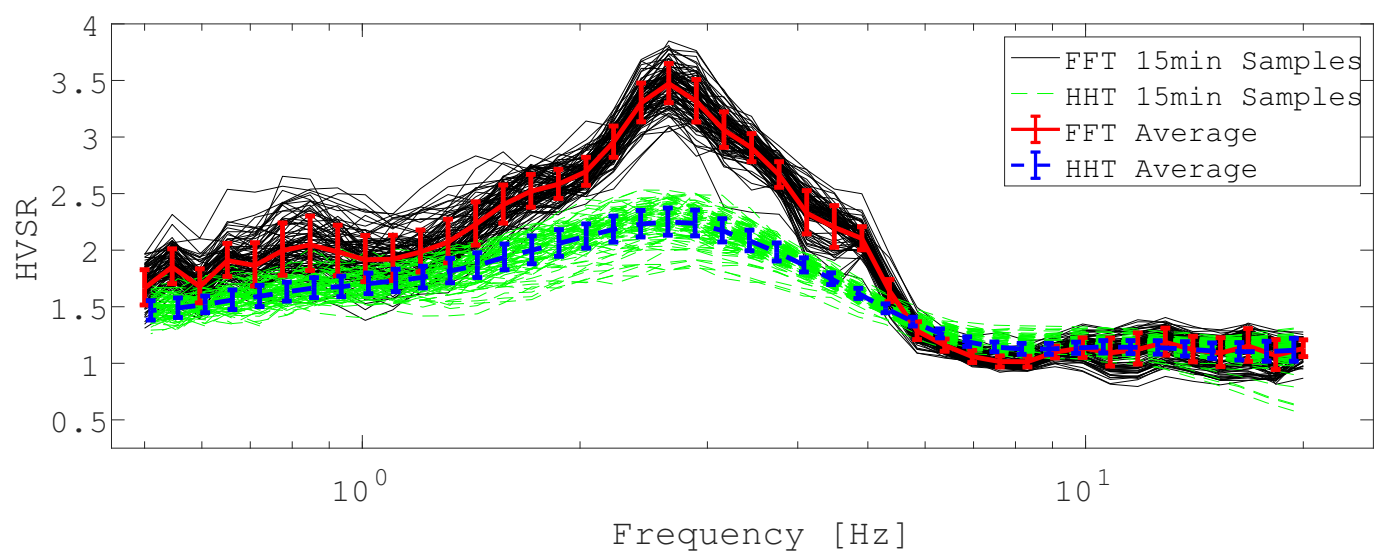

Figure 2. ICJA results for FFT- and MEMD-based processing.

Results are somewhat different, with the FFT-based method estimating more details (even though smoothing according to [38] applies) than the MEMD results (which are not smoothed). Confidence estimates appear similar (judging from standard deviation) but estimates are not overlapping, suggesting considerable disagreement between the methods results with regard to the shape of the HVSR curve. Nevertheless, both methods agree very well with the peak frequency at around $2.7 \mathrm{~Hz}$, albeit the FFT results in a larger peak amplitude.

\subsubsection{Inversion and Comparison}

We invert our HVSR processing results with the computer code by [39] following the Diffuse Field Assumption [40,41]. The used code has been slightly modified to invert for the logarithmic HVSR and to use the corresponding covariance matrix. We only use every second data point, a total of 22 data points per method, in order to aid the inversion with faster convergence. A total of 350 inversions have been run for each, the FFT- and MEMD-based, HVSR estimates with 350 random starting models bounded by the initial 
parameter ranges $v_{i}$ given in Table 1 , where each starting model was used once for both methods. During the inversion, model parameters had to remain within bounds between 50 and $4000 \mathrm{~ms}^{-1}$. The inversions evaluated more than 150,000 models for each algorithm and all models contribute to the final statistics.

We define a weight $p_{r}$ to each model based on its achieved $\chi_{r}^{2}$ misfit for an algorithm's HVSR estimate during the inversion run $r$. First, we transform $\chi^{2}$ for each method:

$$
\tilde{\chi}_{r}^{2}=\frac{\chi_{r}^{2}}{\min \left(\chi^{2}\right)}-1
$$

where $\tilde{\chi}^{2}=0$ is defined as the best achieved (and therefore the practically most likely) model for the respective method. $\tilde{\chi}^{2}$ is used to compare the models obtain from one method and to define the weights for that method. The misfit measure $\chi^{2}$ is used to compare the performance between the two methods. Then, model weights are defined for each method by:

$$
p_{r}=\operatorname{normalise}_{r}\left(\exp \left(-0.5 \tilde{\chi}_{r}^{2}\right)\right) .
$$

The weighted distribution of $\chi^{2}$ for each algorithm is illustrated in Figure 3.

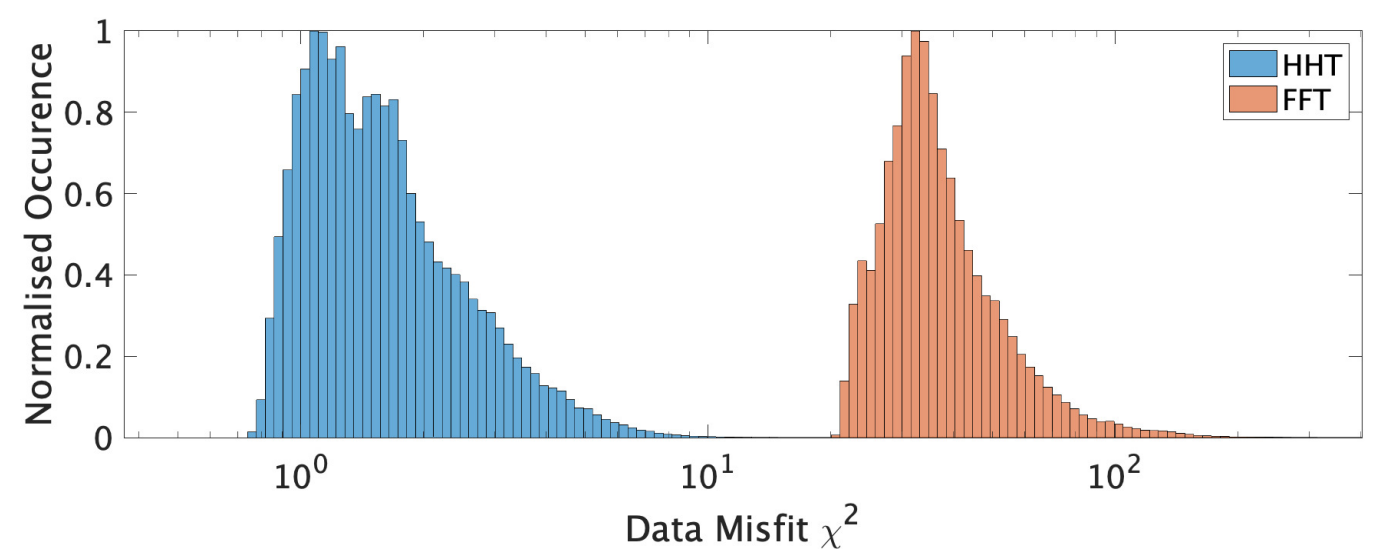

Figure 3. Weighted distribution of tested ICJA inversion models' $\chi^{2}$ for FFT and MEMD curves.

It can be appreciated that MEMD generally achieved a much lower (factor 25) data misfit during all inversions. The HVSR forward computations, the best Vs models, the weighted (for each layer $l$ ) average shear wave velocity $\bar{v}_{l}$ :

$$
\bar{v}_{l}=\sum_{r} v_{l, r} p_{r}
$$

and the weighted standard deviation $\bar{\sigma}_{l}$ :

$$
\bar{\sigma}_{l}=\sqrt{\sum_{r}\left(\left|v_{l, r}-\bar{v}_{l}\right|^{2} p_{r}\right)}
$$

are shown for FFT in Figure 4 and for MEMD they are displayed in Figure 5. 

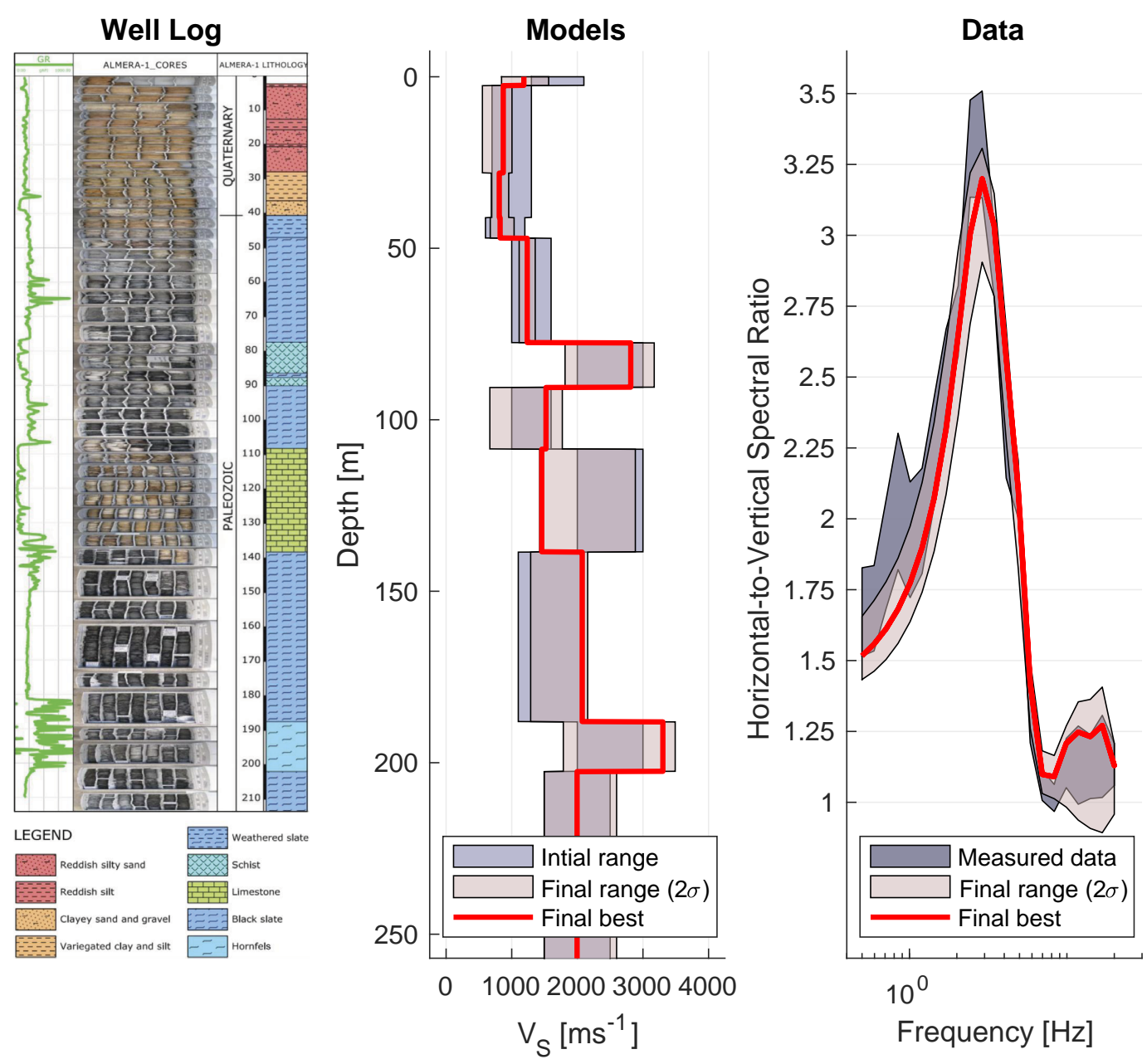

Figure 4. Well-log, models and data for ICJA station obtained with FFT. Well-log column taken from [35].

Both final model estimates are qualitatively similar in the sense that the three high velocity layers are required to fit the data. MEMD data inversions yield higher confidence (smaller variance estimates) suggesting that model variation is well constrained to allow the good fit (cf. data panel in Figure 5). Larger confidence intervals for FFT-based data inversions suggest that a larger range of models fit the data equally poor (cf. data panel Figure 4) and that the inversion is unable to find any model that is more appropriate for the given data. It appears to be more difficult for the inversion algorithm to find a good model to fit the FFT result presumably due to the higher detail in the curve and the particularly high estimates around the peak frequency. Given that the final model ranges agree between FFT, MEMD and our expectations from the lithologic column of the well-log, we judge that the MEMD algorithm provides the better HVSR estimates due to its better data fit and higher confidence estimates in the recovered Vs model compared to the FFT result. A reason for the better performance of the MEMD algorithm could be that, in the present urban environment, the FFT estimates are biased by the complex wavefield which may not comply sufficiently with the required stationarity assumption. 

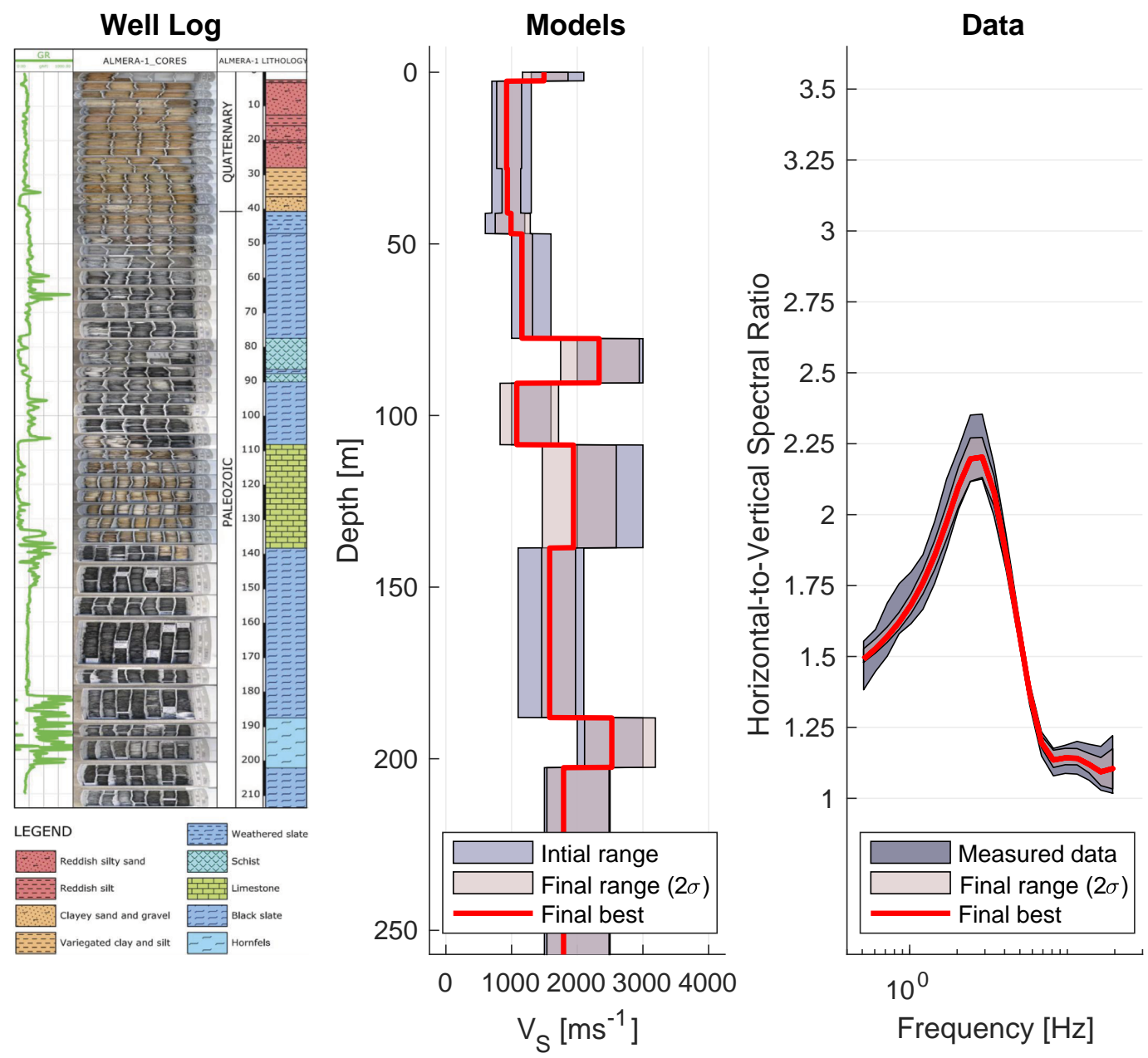

Figure 5. Well-log, models and data for ICJA station obtained with MEMD. Well-log column taken from [35].

\subsection{Tests at the Station EJDN in a Rural Area of El Ejido (Almería, Spain)}

\subsubsection{Introduction and A-Priori Information}

The site EJDN belongs to a temporal seismic array installed from 2006 to 2019 in a Mediterranean coastal plain of Spain. It was equipped with a $120 \mathrm{~s}$ Güralp 3ESPDC broad band seismometer. The station was installed at a rural area in the municipality of El Ejido [5]. The shallow ground structure of this area mainly consists of a series of Pliocene-Miocene sediments and soft sedimentary rocks, often overlaid by Quaternary conglomerates or Pliocene calcarenites, and below a clear impedance contrast is related to stiffer layers of Tortonian calcarenites and Triassic limestone and dolomites. Lithological data at EJDN obtained from a borehole are available from the database of wells managed by the Spanish Geological Survey (http:/ / info.igme.es/BDAguas / (accessed on 1 February 2021)) under the site code 2244-1-0017. Table 2 summarizes the well-log lithology into 7 layers and displays the starting model parameter ranges for the inversions that we will describe later. The starting model parameter range has been determined based on expected values for the given lithologic units and the obtained HVSR curves. During the inversions, Vs values are allowed to range from $200 \mathrm{~ms}^{-1}$ to $3500 \mathrm{~ms}^{-1}$ for all layers and each layer's thickness is bound by layer bottom depth. 
Table 2. Well-log lithology and HVSR inversion initial Vs models from the EJDN station are summarized. Initial models were generated randomly in the Vs range $v_{i} \pm \Delta v_{i}$ and bottom depth range $d_{i} \pm \Delta d_{i}$. During the inversion, model parameters had to remain within the given bounds.

\begin{tabular}{rcccc}
\hline & \multicolumn{2}{c}{ Depth [m] } & \multicolumn{2}{c}{ Vs [m/s] } \\
\hline Lithology & $\boldsymbol{d}_{\boldsymbol{i}} \pm \boldsymbol{\Delta} \boldsymbol{d}_{\boldsymbol{i}}$ & Bounds & $\boldsymbol{v}_{\boldsymbol{i}} \pm \boldsymbol{\Delta} \boldsymbol{v}_{\boldsymbol{i}}$ & Bounds \\
\hline \multirow{2}{*}{ Conglomerate, Sand, Silt and Clay } & $5 \pm 2$ & 0 to 10 & $500 \pm 100$ & 200 to 3500 \\
& $14 \pm 6$ & 0 to 30 & $1050 \pm 250$ & 200 to 3500 \\
\hline Sand and Gravel & $30 \pm 9$ & 0 to 150 & $800 \pm 200$ & 200 to 3500 \\
Sand and Marl & $170 \pm 0$ & fixed at 170 & $1150 \pm 350$ & 200 to 3500 \\
Calcarenite & $264 \pm 0$ & fixed at 264 & $1300 \pm 400$ & 200 to 3500 \\
\hline Limestone \& Dolomite & $950 \pm 150$ & 700 to 1200 & $1700 \pm 500$ & 200 to 3500 \\
Basement & \multicolumn{2}{c}{ NA } & $2200 \pm 500$ & 200 to 3500 \\
\hline
\end{tabular}

\subsubsection{Data Preparation and Processing}

Data at the EJDN station were collected at $100 \mathrm{~Hz}$ for an extended period of time. However, for the purpose of testing and comparing our algorithm, we selected the $3 \mathrm{C}$ measurements of a single day. The chosen day is Christmas day (25 December), 2016, because this is a presumably quiet Sunday with complete data for the entire $24 \mathrm{~h}$. The whole day's data have been divided into 96 intervals of $15 \mathrm{~min}$ and each interval has been processed by MEMD and FFT, as with the previous example.

At 55 frequencies in the range from 0.3 to $30 \mathrm{~Hz}$, we obtain windowed HVSR estimates for both methods which are used to determine a weighted average result for the day, including data confidence in the form of the covariance matrix as described in the previous section. Processing results for both methods are illustrated in Figure 6.

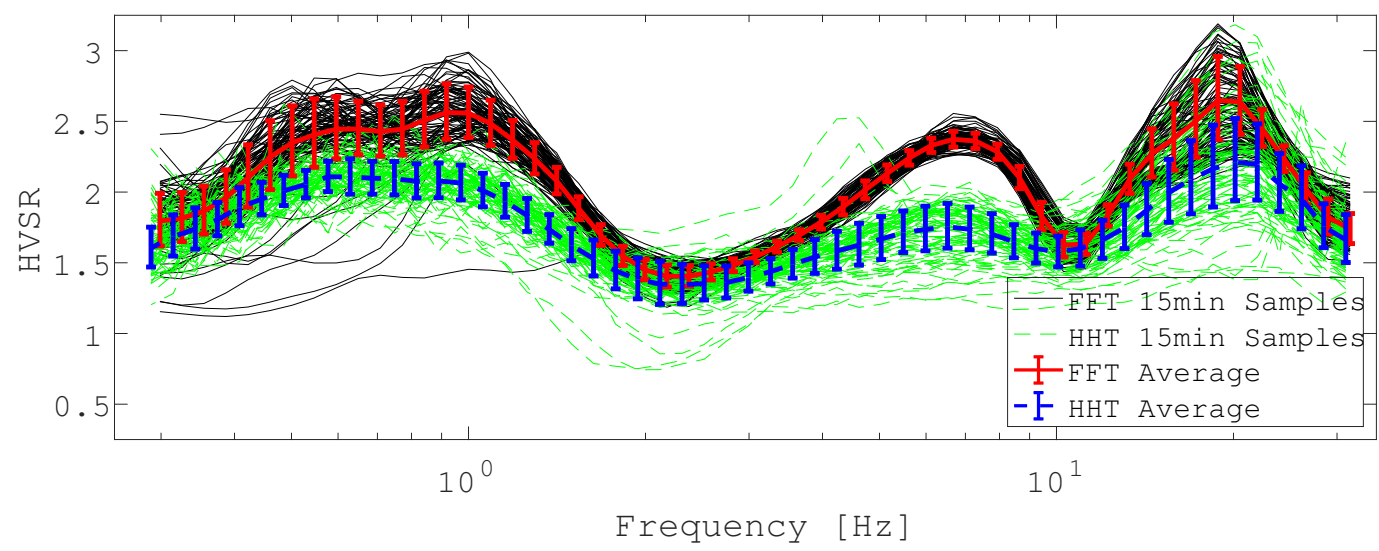

Figure 6. EJDN results for FFT- and MEMD-based processing.

The obtained HVSR curves for the EJDN data differ between the algorithms. Confidence estimates appear generally similar (judging from standard deviation) but FFT estimates a significantly higher confidence for the peak at $8 \mathrm{~Hz}$. Interestingly, the azimuthal variability in amplitude of the $8 \mathrm{~Hz}$ peak, evaluated by the FFT method is high (not shown here), suggesting non-ideal wavefield conditions in this band or non-1D behavior. Estimates between the methods rarely overlap, suggesting considerable disagreement between the methods' results with regard to the shape of the HVSR curve. Nevertheless, both methods agree very well with the multiple peak (and trough) frequencies at around $0.6 \mathrm{~Hz}$, $0.9 \mathrm{~Hz}, 8 \mathrm{~Hz}$, and $20 \mathrm{~Hz}$, albeit the FFT estimates generally larger peak amplitudes.

\subsubsection{Inversion and Comparison}

For the EJDN data inversion, we used every third datum point for a total of 19 datum points. The 80 inversions have been run for FFT- and MEMD-based HVSR estimates with 80 random starting models bounded by the initial parameter ranges $v_{i}$ given in Table 2 . 
More than 350,000 models were evaluated for each algorithm and all models contribute to the final statistics. The weighted distribution of $\chi^{2}$ is illustrated in Figure 7.

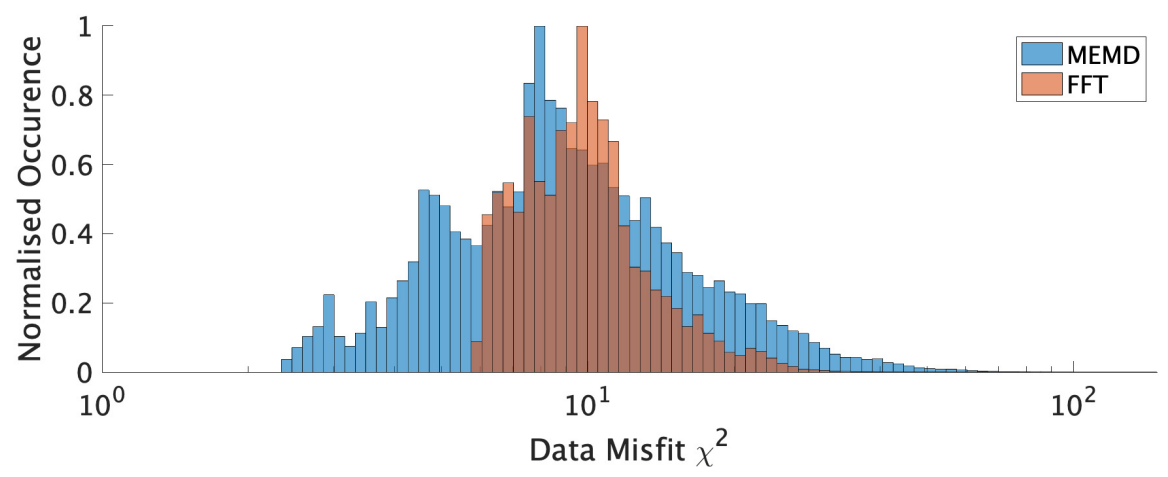

Figure 7. Weighted distribution of tested EJDN inversion models' $\chi^{2}$ for FFT and MEMD curves.

It can be appreciated that MEMD generally achieved a lower (approximately factor 2 on average) data misfit during most inversions. The HVSR forward computations, the best Vs models, the weighted (for each layer $l$ ) average shear wave velocity $\bar{v}_{l}$ and the weighted standard deviation $\bar{\sigma}_{l}$ are shown in Figure 8 , and in Tables 3 and 4.
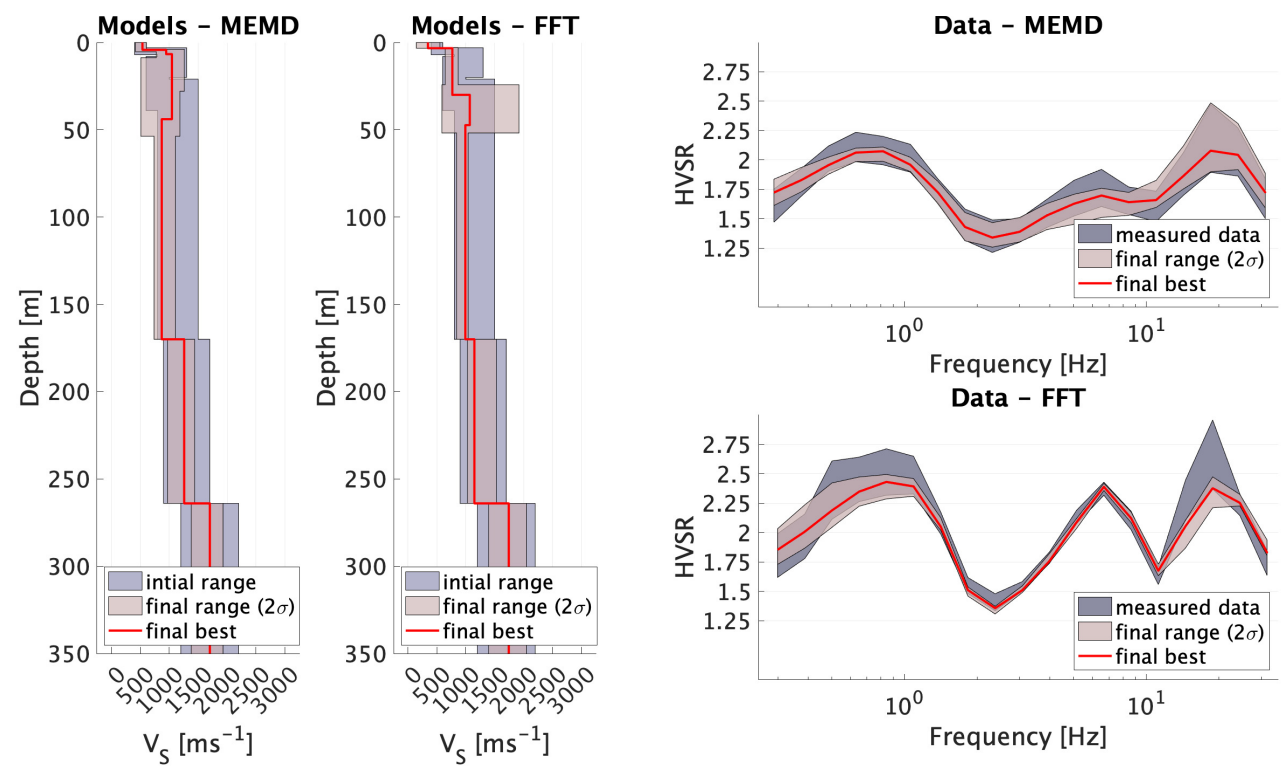

Figure 8. Model results and data fit for the inversion of EJDN data processed by MEMD and FFT.

Both final model estimates are qualitatively similar in the sense that the strong impedance contrasts at 3 to $4 \mathrm{~m}$ and at the $264 \mathrm{~m}$ interface are required to fit the data. Model confidence in both methods' models and associated data fit are very similar. MEMD data inversions yield generally lower Vs values, probably due to the lower peak amplitudes. A notable difference between the two methods' results are the very near surface layers from $5 \mathrm{~m}$ to $50 \mathrm{~m}$. MEMD data supports high Vs $\left(\approx 1000 \mathrm{~ms}^{-1}\right)$ for a thicker layer (though it is not required), while FFT data requires this potential high velocity layer $\left(\approx 1200 \mathrm{~ms}^{-1}\right)$ to create a third large velocity contrast at $30 \mathrm{~m}$. Unfortunately, the well-log lithology record lacks the required level of detail at these depths. More data from other sources would be necessary in order to determine which processing method performed better for this site. Nevertheless, we note that the overall data misfit was better for the MEMD processing results. 
Table 3. Well-log lithology and HVSR inversion final Vs models from the EJDN station are summarized for data obtained by MEMD. The best model (depth, $d_{\text {best }}$, and Vs, $v_{\text {best }}$ ), and the mean model with standard deviation (depth, $\bar{d} \pm \sigma_{d}$, and $\mathrm{Vs}, \bar{v} \pm \sigma_{v}$ ) are displayed.

\begin{tabular}{lcccc}
\hline Lithology & $d_{\text {best }}[\mathrm{m}]$ & $\boldsymbol{v}_{\text {best }}[\mathrm{m} / \mathbf{s}]$ & $\bar{d} \pm \sigma_{d}[\mathrm{~m}]$ & $\bar{v} \pm \sigma_{v}[\mathrm{~m} / \mathbf{s}]$ \\
\hline Conglomerate, Sand, Silt and Clay & 4.2 & 536 & $4.6 \pm 0.8$ & $510 \pm 48$ \\
& 6.7 & 946 & $18.3 \pm 8.2$ & $1017 \pm 121$ \\
\hline Sand and Gravel & 43.9 & 1046 & $40.5 \pm 10.0$ & $847 \pm 169$ \\
Sand and Marl & 170.0 & 869 & $170.0 \pm 0.0$ & $922 \pm 93$ \\
Calcarenite & 264.0 & 1258 & $264.0 \pm 0.0$ & $1204 \pm 117$ \\
\hline Limestone \& Dolomite & 709.8 & 1703 & $802.1 \pm 149.5$ & $1655 \pm 138$ \\
Basement & NA & 2061 & NA & $1839 \pm 259$ \\
\hline
\end{tabular}

Table 4. Well-log lithology and HVSR inversion final Vs models from the EJDN station are summarized for data obtained by FFT. The best model (depth, $d_{\text {best }}$, and Vs, $v_{\text {best }}$ ), and the mean model with standard deviation (depth, $\bar{d} \pm \sigma_{d}$, and $\mathrm{Vs}, \bar{v} \pm \sigma_{v}$ ) are displayed.

\begin{tabular}{lcccc}
\hline Lithology & $d_{\text {best }}[\mathrm{m}]$ & $\boldsymbol{v}_{\text {best }}[\mathrm{m} / \mathbf{s}]$ & $\bar{d} \pm \sigma_{d}[\mathrm{~m}]$ & $\overline{\boldsymbol{v}} \pm \sigma_{v}[\mathrm{~m} / \mathbf{s}]$ \\
\hline Conglomerate, Sand, Silt and Clay & 3.3 & 344 & $3.1 \pm 0.2$ & $348 \pm 101$ \\
& 30.0 & 767 & $27.3 \pm 3.1$ & $755 \pm 56$ \\
\hline Sand and Gravel & 47.3 & 1069 & $44.4 \pm 7.4$ & $1254 \pm 334$ \\
Sand and Marl & 170.0 & 992 & $170.0 \pm 0.0$ & $940 \pm 50$ \\
Calcarenite & 264.0 & 1148 & $264.0 \pm 0.0$ & $1279 \pm 124$ \\
\hline Limestone \& Dolomite & 720.1 & 1744 & $793.2 \pm 112.9$ & $1724 \pm 164$ \\
Basement & NA & 1994 & NA & $1893 \pm 266$ \\
\hline
\end{tabular}

\section{Discussion and Conclusions}

The Horizontal-to-Vertical Spectral Ratio (HVSR) of three component (3C) ambient vibration measurements is a common tool to explore near surface shear wave velocity (Vs) structure. HVSR is often applied for earthquake risk assessments and civil engineering projects. Recorded ambient vibration signal originates from the combination of a multitude of natural and man-made sources, which do not need to be strictly stationary even during short times.

Several aspects of ambient noise such as its azimuthal isotropy, e.g., [42], the energy partition between different vibration modes, e.g., [43] and the stationarity, e.g., [44,45] have been investigated in previous work. Even though clear daily and weekly patterns are found in seismic noise in populated areas, e.g., [46], it often appears quasi-stationary during periods of a few hours in time scales of $10^{3}$ to $10^{4} \mathrm{~s}$ according to [42] for natural illumination. Use of longer records, stationarity test and algorithms suitable for non-stationary signals such as our HHT-based scheme are recommended for applications in urban areas.

Typically, the Fast Fourier Transform (FFT) is applied to obtain spectral information from the measured time series in order to estimate the HVSR but non-stationarity may bias the FFT spectra and HVSR estimates. We described a strategy to process ambient vibration measurements applying the Hilbert-Huang Transform (HHT) instead of FFT. The application of HHT is made possible by realizing that for $3 \mathrm{C}$ measurements a multivariate approach is required to ensure that all three components, i.e., the three instantaneous amplitudes, correspond to one spectral basis, i.e., the same instantaneous frequency. We lay out a robust statistic framework to obtain mean HVSR estimates and the corresponding covariance matrix directly from the instantaneous parameters through HHT without any need for FFT. The procedure is illustrated on measurements from a permanent station situated in a dense urban environment and results are compared to traditional FFT estimates. FFT and HHT results are compared by their estimates' performance in a Vs model inversion, where the Vs models are corroborated by available well-log lithology and a vertical seismic profile. Our HHT-based inversion models yield a lower data misfit $\chi^{2}$ by a factor of up to 25, a more appropriate Vs model and a higher confidence in the achieved model in comparison to FFT-based results. While the conclusions from an experiment at 
only one single site may not allow to claim that the presented strategy is an improvement for general data, it does illustrate that there exist use cases for which the longer data processing time associated with our strategy may be warranted. While we present the same analysis for a second example, our available well-log lithology proved insufficiently detailed to provide conclusive arguments in favor of (or against) our strategy.

In a future work, it would be interesting to investigate if the differences between FFTand HHT-based methods increase for "worse" illumination conditions such as anisotropic wave fields, near sources, etc., and if these methods converge to the same curve in an ideal "stationary" synthetic dataset.

Author Contributions: Conceptualization, M.N. and A.V.; methodology, M.N.; software, M.N., A.G.-J.; validation, M.N., A.G.-J. and F.L.; formal analysis, M.N.; investigation, M.N.; resources, A.V.; data curation, M.R., A.G.-J., L.M.; writing—original draft preparation, M.N.; writing—review and editing, M.N., A.G.-J., F.L., M.R.; visualization, M.N.; supervision, A.V.; project administration, A.V., M.N.; funding acquisition, A.V. All authors have read and agreed to the published version of the manuscript.

Funding: This work was funded by TOTAL under the framework of the Orogen project, with funding from the Spanish government through the 'Severo Ochoa Centre of Excellence' accreditation (CEX2019-000928-S) and the research team RNM-194 of Junta de Andalucía (Spain). Data from station EJDN were obtained in the context of the CGL2014-59908-JIN project, founded by the Spanish Ministry of Economy and Competitiveness and the European Regional Development Fund.

Institutional Review Board Statement: Not applicable.

Informed Consent Statement: Not applicable.

Data Availability Statement: Data used in this work can be obtained by contacting labsis@geo3bcn. csic.es (for ICJA) or agarcia-jerez@ual.es (for EJDN).

Acknowledgments: We would like to acknowledge the GEO3BCN-CSIC Seismic Laboratory at http:/ /labsis.geo3bcn.csic.es/ (accessed on 2 May 2020) for making data of their seismic station ICJA [31] available.

Conflicts of Interest: The authors declare no conflict of interest. The funders had no role in the design of the study; in the collection, analyses or interpretation of data; in the writing of the manuscript, or in the decision to publish the results.

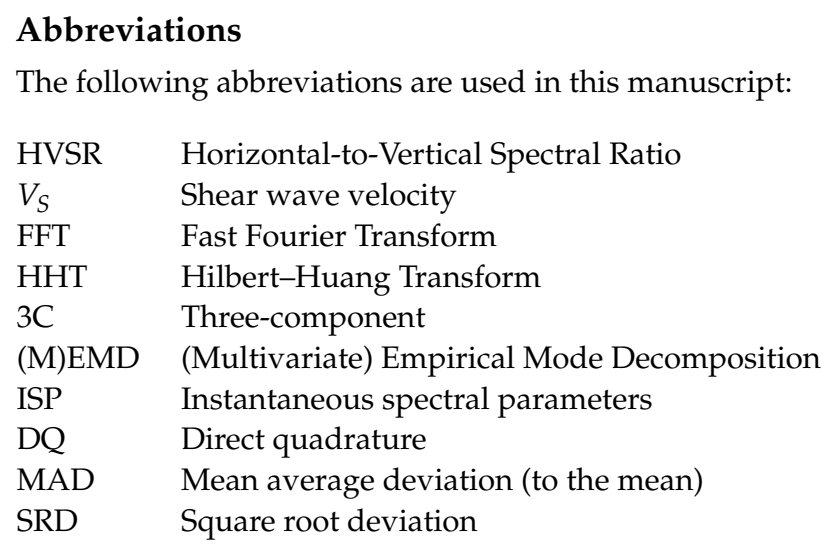

\section{References}

1. Nakamura, Y. A method for dynamic characteristics estimation of subsurface using microtremor on the ground surface. Railw. Tech. Res. Inst. Q. Rep. 1989, 30, 25-33.

2. Bonnefoy-Claudet, S.; Cornou, C.; Bard, P.Y.; Cotton, F.; Moczo, P.; Kristek, J.; Fäh, D. H/V ratio: A tool for site effects evaluation. Results from 1-D noise simulations. Geophys. J. Int. 2006, 167, 827-837. [CrossRef]

3. Lunedei, E.; Malischewsky, P. A Review and Some New Issues on the Theory of the H/V Technique for Ambient Vibrations (Chapter 15). In Perspectives on European Earthquake Engineering and Seismology; Springer: Berlin/Heidelberg, Germany, 2015; pp. 371-394. 
4. Ugalde, A.; Egozcue, J.J.; Ranero, C.R. A new autoregressive moving average modeling of H/V spectral ratios to estimate the ground resonance frequency. Eng. Geol. 2021, 280. [CrossRef]

5. García-Jerez, A.; Seivane, H.; Navarro, M.; Martínez-Segura, M.; Piña-Flores, J. Joint analysis of Rayleigh-wave dispersion curves and diffuse-field HVSR for site characterization: The case of El Ejido town (SE Spain). Soil Dyn. Earthq. Eng. 2019, 121, 102-120.

6. Tumurbaatar, Z.; Miura, H.; Tsamba, T. Site effect assessment in Ulaanbaatar, Mongolia through inversion analysis of microtremor $\mathrm{H} / \mathrm{V}$ spectral ratios. Geoscience 2019, 9, 228. [CrossRef]

7. Tian, B.; Du, Y.; You, Z.; Zhang, R. Measuring the sediment thickness in urban areas using revised H/V spectral ratio method. Eng. Geol. 2019, 260, 105223. [CrossRef]

8. Spica, Z.J.; Perton, M.; Martin, E.R.; Beroza, G.C.; Biondi, B. Urban Seismic Site Characterization by Fiber-Optic Seismology. Sci. Adv. 2020, 1-29. [CrossRef]

9. Mi, B.; Hu, Y.; Xia, J.; Socco, L.V. Estimation of horizontal-to-vertical spectral ratios (ellipticity) of Rayleigh waves from multistation active-seismic records. Geophysics 2019, 84, EN81-EN92. [CrossRef]

10. Hloupis, G.; Vallianatos, F.; Stonham, J. A wavelet representation of HVSR. Bull. Geol. Soc. Greece 2004, 36, 1269-1278. [CrossRef]

11. Carniel, R.; Malisan, P.; Barazza, F.; Grimaz, S. Improvement of HVSR technique by wavelet analysis. Soil Dyn. Earthq. Eng. 2008, 28, 321-327.

12. Liu, L.; Mehl, R.; Wang, W.; Chen, Q.F. Applications of the Hilbert-Huang transform for microtremor data analysis enhancement. J. Earth Sci. 2015, 26, 799-806. [CrossRef]

13. Harsuko, M.R.C.; Zulfakriza, Z.; Nugraha, A.D.; Sarjan, A.F.N.; Widiyantoro, S.; Rosalia, S.; Puspito, N.T.; Sahara, D.P. Investigation of Hilbert-Huang Transform and Fourier Transform for Horizontal-to-Vertical Spectral Ratio Analysis: Understanding the Shallow Structure in Mataram City, Lombok, Indonesia. Front. Earth Sci. 2020, 8. [CrossRef]

14. Huang, N.E.; Shen, Z.; Long, S.R.; Wu, M.C.; Snin, H.H.; Zheng, Q.; Yen, N.C.; Tung, C.C.; Liu, H.H. The empirical mode decomposition and the Hilbert spectrum for nonlinear and non-stationary time series analysis. Proc. R. Soc. A Math. Phys. Eng. Sci. 1998, 454, 903-995. [CrossRef]

15. Rai, V.K.; Mohanty, A.R. Bearing fault diagnosis using FFT of intrinsic mode functions in Hilbert-Huang transform. Mech. Syst. Signal Process. 2007, 21, 2607-2615. [CrossRef]

16. Jackson, L.P.; Mound, J.E. Geomagnetic variation on decadal time scales: What can we learn from Empirical Mode Decomposition? Geophys. Res. Lett. 2010, 37, 1-6. [CrossRef]

17. Gairola, G.S.; Chandrasekhar, E. Heterogeneity analysis of geophysical well-log data using Hilbert-Huang transform. Phys. A Stat. Mech. Its Appl. 2017, 478, 131-142. [CrossRef]

18. Zhu, C.; Cotton, F.; Pilz, M. Detecting Site Resonant Frequency Using HVSR: Fourier versus Response Spectrum and the First versus the Highest Peak Frequency. Bull. Seismol. Soc. Am. 2020, 1-14. [CrossRef]

19. Horike, M.; Zhao, B.; Kawase, H. Comparison of site response characteristics inferred from microtremors and earthquake shear waves. Bull. Seismol. Soc. Am. 2001, 91, 1526-1536.

20. Mucciarelli, M.; Gallipoli, M.R.; Arcieri, M. The stability of the horizontal-to-vertical spectral ratio of triggered noise and earthquake recordings. Bull. Seismol. Soc. Am. 2003, 93, 1407-1413.

21. Parolai, S.; Picozzi, M.; Strollo, A.; Pilz, M.; Di Giacomo, D.; Liss, B.; Bindi, D. Are Transients Carrying Useful Information for Estimating H/V Spectral Ratios? In Increasing Seismic Safety by Combining Engineering Technologies and Seismological Data; Mucciarelli, M., Herak, M., Cassidy, J., Eds.; Springer: Dordrecht, The Netherlands, 2009; pp. 17-31.

22. Rodriguez, V.H.; Midorikawa, S. Applicability of the H/V spectral ratio of microtremors in assessing site effects on seismic motion. Earthq. Eng. Struct. Dyn. 2002, 31, 261-279. [CrossRef]

23. D'Alessandro, A.; Luzio, D.; Martorana, R.; Capizzi, P. Selection of time windows in the horizontal-to-vertical noise spectral ratio by means of cluster analysis. Bull. Seismol. Soc. Am. 2016, 106, 560-574. [CrossRef]

24. Rehman, N.; Mandic, D.P. Multivariate empirical mode decomposition. Proc. R. Soc. A Math. Phys. Eng. Sci. 2010, 466, 1291-1302. [CrossRef]

25. Candra, A.D.; Suryani, P.E. Application of Multivariate Empirical Mode Decomposition to Noise Reduction in Seismic Signal. J. Phys. Conf. Ser. 2019, 1204. [CrossRef]

26. Neukirch, M.; Garcia, X. Nonstationary magnetotelluric data processing with instantaneous parameter. J. Geophys. Res. Solid Earth 2014, 119. [CrossRef]

27. Goncalves, P.; Rilling, G.; Flandrin, P. On empirical mode decomposition and its algorithms. IEEE-EURASIP Workshop Nonlinear Signal Image Process. 2003, 3, 8-11. [CrossRef]

28. Huang, N.E.; Wu, Z.; Long, S.R.; Arnold, K.C.; Chen, X.; Blank, K. On Instantaneous Frequency. Adv. Adapt. Data Anal. 2009, 01, 177-229. [CrossRef]

29. Galassi, M.; Davies, J.; Theiler, J.; Gough, B.; Jungman, G.; Alken, P.; Booth, M.; Rossi, F.; Ulerich, R. GNU Scientific Library, Reference Manual Version 1.15. 2015. Available online: http:/ /www.gnu.org/software/gsl (accessed on 12 November 2020).

30. Neukirch, M.; Garcia, X. On the effect of non stationary (synthetic) sources in the magnetotelluric method. In EGU General Assembly Conference Abstracts; Copernicus Gesellschaft mbH: Göttingen, Germany, 2013; p. EGU2013-10590. Available online: https:/ /cdn.egu.eu/media/awards/union-osp-award/2013/maik_neukirch.pdf (accessed on 8 May 2021).

31. Diaz, J.; Pulgar, J.A. MISTERIOS. 2015. Available online: http://www.fdsn.org/networks/detail/2M_2015/ (accessed on 8 May 2021). 
32. Díaz, J.; Ruiz, M.; Sánchez-Pastor, P.S.; Romero, P. Urban Seismology: On the origin of earth vibrations within a city. Sci. Rep. 2017, 7, 1-11. [CrossRef] [PubMed]

33. Diaz, J.; Ruiz, M.; Jara, J.A. Seismic monitoring of urban activity in Barcelona during the COVID-19 lockdown. Solid Earth 2021, $12,725-739$.

34. Teixido, T.; Jurado, M.J. Tomografía sísmica vertical inversa 2.5D alrededor del sondeo científico Almera-1, ICTJA-CSIC, Barcelona. IX Congr. Geol. Esp. 2016, 16, 609-612.

35. Jurado, M.J.; Salvany, J.M. Scientific drilling in the campus: Almera-1 borehole, unraveling urban subsurface geology in Barcelona (Spain). Perforación científica en el campus: Almera-1 un sondeo para investigación del subsuelo urbano Llobregat delta. IX Congr. Geol. Esp. 2016, 16, 617-620.

36. Wathelet, M.; Chatelain, J.L.; Cornou, C.; Giulio, G.D.; Guillier, B.; Ohrnberger, M.; Savvaidis, A. Geopsy: A User-Friendly OpenSource Tool Set for Ambient Vibration Processing. Seismol. Res. Lett. 2020, 91, 1878-1889. [CrossRef]

37. SESAME. Guidelines for the Implementation of the H/V Spectral Ratio Technique on Ambient Vibrations-Measurements, Processing and Interpretations, SESAME European Research Project EVG1-CT-2000-00026, Deliverable D23.12; Technical Report; European Commission: Brussels, Belgium, 2004.

38. Konno, K.; Ohmachi, T. Ground-motion characteristics estimated from spectral ratio between horizontal and vertical components of microtremor. Bull. Seismol. Soc. Am. 1998, 88, 228-241.

39. García-Jerez, A.; Piña-Flores, J.; Sánchez-Sesma, F.J.; Luzón, F.; Perton, M. A computer code for forward calculation and inversion of the H/V spectral ratio under the diffuse field assumption. Comput. Geosci. 2016, 97, 67-78. [CrossRef]

40. Sánchez-Sesma, F.J.; Rodríguez, M.; Iturrarán-Viveros, U.; Luzón, F.; Campillo, M.; Margerin, L.; García-Jerez, A.; Suarez, M.; Santoyo, M.A.; Rodríguez-Castellanos, A. A theory for microtremor H/V spectral ratio: Application for a layered medium. Geophys. J. Int. 2011, 186, 221-225. [CrossRef]

41. Piña-Flores, J.; Perton, M.; García-Jerez, A.; Carmona, E.; Luzón, F.; Molina-Villegas, J.C.; Sánchez-Sesma, F.J. The inversion of spectral ratio H/V in a layered system using the diffuse field assumption (DFA). Geophys. J. Int. 2017, 208, 577-588. [CrossRef]

42. Mulargia, F. The seismic noise wavefield is not diffuse. J. Acoust. Soc. Am. 2012, 131, 2853-2858. [CrossRef]

43. Piña-Flores, J.; Cárdenas-Soto, M.; García-Jerez, A.; Campillo, M.; Sánchez-Sesma, F. The Search of Diffusive Properties in Ambient Seismic Noise. Bull. Seismol. Soc. Am. 2021, in press. [CrossRef]

44. Sax, R.L. Stationarity of Seismic Noise. Geophysics 1968, 33, 668-674. [CrossRef]

45. Wang, D.; Li, Y.; Nie, P. A study on the Gaussianity and stationarity of the random noise in the seismic exploration. J. Appl. Geophys. 2014, 109, 210-217. [CrossRef]

46. Bonnefoy-Claudet, S. Nature du bruit de fond sismique: Implications pour les études des effets de site. Ph.D. Thesis, Université Joseph-Fourier, Grenoble, France, 2004. 